\title{
Evaluation of wet and dry event's trend and instability based on the meteorological drought index
}

\author{
Muhammad Haroon Shaukat ${ }^{1}$, Ahmad Al-Dousari ${ }^{2}$, Ijaz Hussain ${ }^{\text {Corresp., } 1}{ }^{1}$, Muhammad Faisal ${ }^{3}$, Muhammad Ismail ${ }^{4}$, \\ Alaa Mohamd Shoukry ${ }^{5,6}$, Elsayed Elsherbini Elashkar ${ }^{7,8}$, Showkat Gani ${ }^{9}$ \\ ${ }^{1}$ Department of Statistics, Quaid-i-Azam University, Islamabad, Pakistan \\ 2 Department of Geography, Kuwait University, Kuwait, Kuwait \\ 3 Faculty of Health Studies, University of Bradford, Bradford, United Kingdom \\ 4 Department of Statistics, COMSATS University Islamabad, Lahore Campus, Lahore, Pakistan \\ ${ }^{5}$ Arriyadh Community College, King Saud University, Riyadh, Saudi Arabia \\ 6 KSA workers University, Nsar, Egypt \\ 7 Administrative Sciences Department, Community College, King Saud University, Riyadh, Saudi Arabia \\ 8 Applied Statistics Department, Faculty of Commerce, Mansoura University, Mansoura, Egypt \\ 9 College of Business Administration, King Saud University, Muzahimiyah, Saudi Arabia \\ Corresponding Author: ljaz Hussain \\ Email address: ijaz@qau.edu.pk \\ A temporal imbalance in the water availability, which is consistently below average or \\ more than average rainfall, can lead to extremely dry or wet conditions. This impacts on \\ agricultural yields, water resources and human activities. Weather instabilities and trends \\ of wet/dry events have not yet been explored in Pakistan. In this study, we have two-fold \\ objectives:1) evaluate the weather instabilities, and 2) the trend of dry/wet events of \\ selected stations of Pakistan. To observe weather instabilities, we used Mean Marginal \\ Hilbert Spectrum (MMHS) and Continuous Wavelet Power Spectrum (CWPS) as \\ meteorological series are mostly non-linear and non-stationary. We used Ensemble \\ Empirical Mode Decomposition (EEMD) for the analysis of temporal characteristics of \\ dry/wet events. We found that all stations are facing severe weather instabilities during \\ the short period of 5 and 10 months using MMHS method and CWPS has shown the \\ weather instabilities during 4 to 32 months of periodicity for all stations. Ultimately, the \\ achieved short-term weather instabilities indicated by MMHS is consistent with CWPS. In \\ summary, these findings might be useful for water resource management and \\ policymakers.
}




\title{
Evaluation of wet and dry event's trend and instability based on the
} meteorological drought index

\author{
Muhammad Haroon Shaukat ${ }^{1}$, Ahmad Al-Dousari², Ijaz Hussain ${ }^{1,}{ }^{*}$, Muhammad Faisal ${ }^{3}$, \\ Muhammad Ismail ${ }^{4}$, Alaa Mohamd Shoukry ${ }^{5,6}$, Elsayed Elsherbini Elashkar ${ }^{7,8}$,Showkat Gani ${ }^{9}$ \\ ${ }^{1}$ Department of Statistics, Quaid-i-Azam University, Islamabad, Pakistan \\ ${ }^{3}$ Faculty of Health Studies, University of Bradford, Bradford BD7 1DP, UK \\ ${ }^{2}$ Department of Geography, Kuwait University, Kuwait, Kuwait. \\ ${ }^{4}$ Department of Statistics, COMSATS University Islamabad, Lahore Campus, Lahore, Pakistan \\ ${ }^{5}$ Arriyadh Community College, King Saud University Riyadh Saudi Arabia. \\ ${ }^{6} \mathrm{KSA}$ workers University, Nsar, Egypt. \\ ${ }^{7}$ Administrative Sciences Department, Community College, King Saud University, Riyadh 11437, Saudi Arabia \\ ${ }^{8}$ Applied Statistics Department, Faculty of Commerce, Mansoura University, Mansoura 35516, Egypt. \\ ${ }^{9}$ College of Business Administration, King Saud University Muzahimiyah,Saudi Arabia. \\ *Corresponding authorE-mail: ijaz@qau.edu.pk
}

\section{Abstract}

A temporal imbalance in the water availability, which is consistently below average or more than average rainfall, can lead to extremely dry or wet conditions. This impacts on agricultural yields, water resources and human activities. Weather instabilities and trends of wet/dry events have not yet been explored in Pakistan. In this study, we have two-fold objectives:1) evaluate the weather instabilities, and 2) the trend of dry/wet events of selected stations of Pakistan. To observe weather instabilities, we used Mean Marginal Hilbert Spectrum (MMHS) and Continuous Wavelet Power Spectrum (CWPS) as meteorological series are mostly non-linear and non-stationary. We used Ensemble Empirical Mode Decomposition (EEMD) for the analysis of temporal characteristics of 
dry/wet events. We found that all stations are facing severe weather instabilities during the short period of 5 and 10 months using MMHS method and CWPS has shown the weather instabilities during 4 to 32 months of periodicity for all stations. Ultimately, the achieved short-term weather instabilities indicated by MMHS is consistent with CWPS. In summary, these findings might be useful for water resource management and policymakers.

Keywords: Drought; Ensemble Empirical Mode Decomposition; Hilbert Hung Transformation; Standardized Precipitation Index; Continuous Wavelet Transform

\section{Introduction}

In recent decades, the climate changes tend to increase the occurrence and intensity of natural perils such as heavy rainfall, flood, forest fires and droughts that indicate an increasing trend (Estrela \& Vargas, 2012; Kreibich et al., 2017; Masud et al., 2020). The consequent trend shows that precipitation makes wet places wetter and dry places drier (Trenberth, 2011), which leads to extremely dry and wet conditions that undesirably influence agricultural productions, water resources and human activities. Among these destructive climate events, drought is a natural hazard, which is a result of a prolonged shortage of precipitation, high temperature and change in the weather pattern. The substantial variability of precipitation in both space and time leads to drought. It is a challenging task to monitor and identify drought due to its dynamic spatio-temporal patterns (Shi et al., 2013).

Several drought indexes are commonly used for the detection and characterization of drought, i.e., Standardized Precipitation Index (SPI) (Mckee et al., 1993), Standardized Anomaly Index (SAI) (Katz \& Glantz, 1986), Standardized Precipitation Evapotranspiration Index (SPEI), (VicenteSerrano et al., 2010) and Reconnaissance Drought Index (RDI) (Tsakiris \& Vangelis, 2005) etc. 
47 Mostly, SPI has been used to identify and monitor drought in previous studies (Bai et al., 2020; T.

48 Caloiero \& Veltri, 2019). SPI is used to measure the precipitation shortage from the long-term

49 historical record of precipitation and represents the quantitative definition of droughts on multiple

50 time scales i.e., 3, 6, 9, 12, 24 and 48 months. Among these time scales, 3-months SPI (SPI-3) is

51 used for a short term, 6-months SPI (SPI-6) is used for medium-term and 48-months SPI (SPI-48)

52 is used for long term drought analysis (Wu et al., 2007). Mostly meteorological and hydrological

53 series have non-linear and non-stationary characteristics (Di et al., 2014). Hilbert Huang

54 Transformation (HHT) procedure is very e $\square$ cient to deal with non-stationary and non-linear data

55 and explain hydrological variability in terms of climate change (Massei \& Fournier, 2012).

56 Empirical Ensemble Mode Decomposition (EEMD) and Continuous Wavelet Transform (CWT)

57 were applied on the two series e.g., daily Seine river flow (1950-2008) in the northern half of

58 France and North Atlantic Oscillation (NAO) (1865-2008) to evaluate the natural variability. The

59 coordination of EEMD with HHT technique was found to be e $\square$ cient for detecting changes in

60 natural variation and characteristic scale of variability. The performance results of both series were

61 indicating a similar characteristic of the scale of variability and seasonality that the amplitude is

62 increasing since the 1970s in both series (Massei \& Fournier, 2012). Bin Li et al., (2013) utilize

63 the data of daily precipitation (1960-2015) of 35 meteorological stations of the lancing river basin

64 in China. The meteorological stations were further distributed into sub-regions by using PCA and

65 K-means clustering. Their study aimed to explore the spatial and temporal pattern with multiple

66 time scales of meteorological drought by using the SPI. The EMD and CWT were used for the

67 analysis of temporal variability. It was found that $60 \%$ of meteorological drought variation is

68 associated with intra-fluctuation decadal, except Chengdu station. Wang et al. (2015) utilized the

69 precipitation data (1957-2012) of 20 meteorological stations of the North-East China Transect 
70 (NECT) region in South China. They applied the cluster analysis on SPI which is based on Discrete

71 Wavelet Transformation (DWT) to consider the temporal evaluation of drought characteristics. It

was reported that cluster analysis is e $\square$ cient for spatial and temporal drought analysis and does not provide information about drought variability but provides beneficial information to water resources management and for agricultural planning. Yang et al. (2019) utilized the Modified Soil Water Deficit Index (MSWDI) of the Songnen Plain in China. Their study aimed to investigate the agricultural drought frequency and trend by HHT. Several studies suggested that HHT approach found to be more e $\square$ ective for decomposing the series into several components through EEMD as compared to Wavelet Transform (WT) (Massei \& Fournier, 2012; Yang et al., 2019). MannKendall (MK) trend test and Spearman's Rho (SR) test were used for the trend analysis of agricultural droughts. As a result, residuals from HHT showed the increasing trend for the year 1981 and a decreasing trend for the year 1961 to 1980. Shahid (2010) utilized the rainfall data (1958-2007) of 17 meteorological stations in Bangladesh. Two non-parametric tests, i.e., MK and Sen.'s slop (SS) tests were used on the SPI to detect a significance and magnitude in wet and dry events in Bangladesh. He found a significant decrease of dry months in monsoon and pre-monsoon.

According to a global vulnerability index report, Pakistan is in the list of the top 10 countries that are highly affected by climate change (Ullah, 2016) as its economy is heavily dependent on the agriculture sector which can severely be affected by climate changes (Ali et al., 2017). In this study, we aimed to evaluate the weather instabilities and the trend of dry/wet events of selected stations of Pakistan.

\section{Methods and materials}

\subsection{Study area}

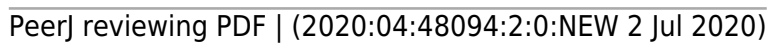


92 The study areas include four meteorological stations (Multan, Bahawalpur, Barkhan and Khanpur)

93 of Pakistan. These selected stations are located in the Southern part of Pakistan, mostly very hot

94 and mildly cold areas. Since our objective is to analyze the trend and weather instabilities with

95 respect to time, therefore, selecting four (stations) time-series data is enough, increasing the

96 number of stations may cause a problem in time series analysis. Monthly quantitative data of

97 precipitation from January 1990 to December 2018 has been obtained from the Karachi Data

98 Processing Center through the Pakistan Meteorological Department, Karachi. The geographical

99 presentation of selected stations is displayed in Figure 1.

\subsection{Standardized Precipitation Index at 3-months (SPI-3)}

101

102

103

104

105

106

107

108

109

110

111

112

113

Mckee et al. (1993) proposed a Standardized Precipitation Index (SPI) for defining and monitoring wet and dry events i.e., beginning, ending and intensity. The SPI is used to measure the precipitation shortage from the long-term historical record of precipitation. In this study, the cumulative precipitation series such as 3 months' time scale is used to calculate SPI. Because, SPI-3 with a short time scale describes droughts, which is important for the agriculture sector (Tommaso Caloiero, 2018; Zhang et al., 2012; Ali et al., 2017).

\subsection{Method for Dry/Wet events trend analysis}

\subsubsection{Empirical Ensemble Mode Decomposition (EEMD)}

Ensemble Empirical Mode Decomposition (EEMD) is an extension of Empirical Mode Decomposition (EMD) (N. E. Huang et al., 1998). EEMD was proposed by (Z. Wu \& Huang, 2009) and which is used to handle the mode mixing problem. Extension in EMD procedure is done through adding white noise in the time series. EEMD is a very e $\square$ ective procedure that minimizes the presence of mode mixing problems in the decomposition phase and is very helpful in separating 
114 frequency scales. EEMD uses the time series to decompose into several stationary Intrinsic Mode

115 Function (IMF) and a residual component. According to (Z. Wu \& Huang, 2009), the EEMD

116 procedure is as follows:

117 - Set the ensemble number $E$ for each case and select the amplitude of white noise.

121 After this, use the traditional EMD method to decompose the new time series $y_{i}(t)$ into the IMFs.

122 The detailed methodology of decomposing series into the IMFs by EMD is described in the (Huang 123 et al., 1998).

\subsection{Methods for Weather instabilities}

\subsubsection{Continuous Wavelet Power Spectrum (CWPS)}

126 Continuous Wavelet Transformation (CWT) is used to represent the frequency in the time domain 127 and determine the temporal variability of the series. Following (Labat, 2005), the mathematical 128 form of CWT is as follows:

$$
W_{\psi}^{y}(\gamma, \tau)=\frac{1}{\sqrt{\gamma}} \int_{-\infty}^{+\infty} y(t) \psi^{*}\left(\frac{t-\tau}{\gamma}\right) d t
$$

130 where $y(t)$ represents the time series, $t$ is time and $\psi^{*}$ represent the complex conjugate of the 131 mother wavelet function. The scale factor $\gamma$ is also known as the frequency that is related to the 132 location of wavelets in the frequency domain and it is used for controlling the width of the wavelet 
133 function. Whereas, $\tau$ the parameter is related to the location of the wavelet in the time domain and 134 it is used for the adjustment of wavelet location. Initially, Morlet wavelet is presented by 135 (Grossmann \& Morlet, 2009) and its mathematical form is defined as:

$$
\psi(t)=\pi^{-\left(\frac{1}{4}\right)} e^{-\left(i \gamma_{0} t\right)} e^{-\left(\frac{-t^{2}}{2}\right)}
$$

137 where $\gamma_{0}$ is a non-dimensional frequency and $i$ is the complex values. (Farge, 1992) suggested

138 that the term $\gamma_{0}$ is the non-dimensional frequency (angular frequency) is set 6 to satisfy the 139 admissible condition.

140 Spectrum construction in the wavelet method is like the Fourier method. But it analyzes spectrum

141 time, frequency and decomposition rather than the time and scale (Lim \& Lye, 2002). According 142 to (Torrence \& Compo, 1998), the Continuous Wavelet Power Spectrum (CWPS) with scale factor 143 is as follows:

$$
P_{w}(\gamma)=\left|W_{\psi}^{y}(\gamma, \tau)\right|^{2}
$$

\subsection{Mean Marginal Hilbert Spectrum (MMHS)}

146 Hilbert Hung Transformation (HHT) was o $\square$ ered by (N. E. Huang et al., 1996). HHT is a very 147 powerful tool and used for dealing with stationary and non-linear series. IMFs are obtained through 148 a decomposition procedure and there is no difficulty in applying the Hilbert Transformation (HT) 149 to obtain instantaneous frequency (IF) and instantaneous amplitude (IA). HT is only applicable for 150 IMFs and not applicable for residual which is a monotonic function. Following (N. E. Huang et 151 al., 2003), we can compute the Hilbert transform $z(t)$ of time series $y(t)$ as: 


$$
z(t)=\frac{1}{\pi} P \int \frac{y\left(t^{\prime}\right)}{t-t^{\prime}} d t^{\prime}
$$

153 where, $P$ is the Cauchy value and HT be present for all the functions of LP class (Bailey \&

154 Titchmarsh, 1938). By definition, the analytical signal $R(t)$ consists of the complex conjugate of $155 y(t)$ and $z(t)$.

$$
R(t)=y(t)+i z(t)=a(t) e^{i \varphi(t)}
$$

157 where,

$$
a(t)=\sqrt{\left(y^{2}(t)+z^{2}(t)\right)}
$$

$$
\varphi(t)=\arctan \left(\frac{z(t)}{y(t)}\right)
$$

160 Where, $a(t)$ represents the superlative local fit of amplitude and $\varphi(t)$ phase varying trigonometric

161 function to $y(t)$ (N. E. Huang et al., 2003). IF is obtained by taking the first order derivative of

162 phase $\varphi(t)$ to time $t$.i.e.,

$$
w=\frac{d \theta(t)}{d t}
$$

164 The IF is a mono-component function in which only one component represents only one frequency.

165 After completion of HT for each IMF, the following structure of the time series is shown as real 166 part:

$$
y(t)=R P\left[\sum_{j=1}^{n} a_{j}(t) e\left(i \int w_{j} t d t\right)\right]
$$


168 HT is not applicable for the residual term (Non-IMF), because residual is a constant term. With an 169 explanation of the HS, it is also very important to define the Mean Marginal Hilbert Spectrum 170 (MMHS). i.e.,

$$
h(\omega)=\int_{0}^{T} H(\omega, t) d t
$$

172 The MMHS presents the contribution of total amplitude which is corresponding to each frequency 173 value.

\subsection{Non-Parametric Trend Tests}

It is very essential to extract the underlying pattern of hydrological and meteorological time series. There are several techniques for identifying patterns and analyzing hydrological meteorological time series trends. The assumptions of parametric test i.e., normality, independence and linearity are not met in the hydrological or meteorological time series. Some non-parametric techniques for dealing with non-normal and non-linear series are available in the literature, such as Mann-Kendall (MK) and Spearman's Rho (SR) trend test.

\subsubsection{Mann-Kendall (MK) Trend Test}

Mann (1945) proposed a non-parametric test which is used to assess the randomness against the

183 trend in hydrology and climatology. According to MK trend test, the null hypothesis $H_{0}$ state that

184 the $\left(y_{1}, y_{2}, \ldots, y_{n}\right)$, are independent and identically distributed sample (there is no trend) and the

185 alternative hypothesis $H_{1}$ states that the distribution of $y_{i}$ and $y_{j}$ are not identical (there is a 186 trend) for all $i \neq j$. As a resultant, the positive value of the test statistics is an indication of an 187 increasing trend which is increasing with respect to time. Whereas, the negative value of the test 
188 statistics is an indication of a decreasing trend which is decreasing with respect to time. Therefore,

189 the test statistic and their theoretical calculation of MK trend test are described in (Hirsch et al., 190 1982).

191

\subsubsection{Spearman's Rho (SR) Trend Test}

192 Spearman's Rho (SR) trend test is based on the rank of observations. SR trend test is used to 193 identify the absence of a linear and non-linear trend. Following (Yang et al., 2019), standardized 194 test statistics are as follows:

$$
d=1-\frac{6 \sum_{i=1}^{n}\left(R\left(y_{i}\right)-i\right)^{2}}{n\left(n^{2}-1\right)}
$$

$$
z_{d}=d \sqrt{\frac{(n-2)}{\left(1-d^{2}\right)}}
$$

197 Where, $R\left(y_{i}\right)$ is the rank of ith observation in the time series. As a resultantly negative value $z_{d}$

198 is an indication of a decreasing trend and the positive value of $z_{d}$ is an indication of an increasing 199 trend. At the 5\% of the level of significance $(a)$, the null hypothesis is rejected (trend exist in the 200 series) if $\left|z_{d}\right|>t_{(n-2,1-a / 2)}$.

\section{Results}

In this paper, the precipitation time series of four meteorological stations (Multan, Bahawalpur, Barkhan and Khanpur) have been used for explaining the wet and dry events periodicity, variability and transient trend. Initially, three months of aggregated precipitation (P-3) series are used for the computation of SPI-3. In the estimation stage, the suitable probability distribution is selected for 
206 all series of four meteorological stations. Hence, the detail of fitting suitable probability

207 distributions on P-3 is described in Table 1.

\section{$208 \quad 3.1$ Trend analysis of wet and dry events}

209 Later, the SPI-3 is decomposed into IMFs by using the EEMD procedure. The decomposition level

210 is based on the total number of observations. There are 348 total observations as the SPI-3 series

211 consists of monthly observations from the year 1990 to 2018. According to (Sang et al., 2016),

$212 \log _{2}(348)$ provides eight levels of decomposition. The ensemble number is set to 100 and the

213 amplitude of white noise is about 0.2 standard deviation has been added in SPI-3 for construction

214 of IMFs by EEMD (Z. Wu \& Huang, 2009). Finally, by applying the EEMD method, SPI-3 of all

215 stations is decomposed into eight IMFs and a residual term, which is depicted in Figure 2.

216 Figure 2 shows the IMF-1 and IMF-2 intra-annual fluctuations with the duration $(<1)$ year for all

217 stations, though the IMF-3 and IMF-4 specifies the Intra-decadal fluctuation with periodicity

218 between (1-3) years and (1-6) years in Multan and Khanpur, respectively. Similarly, the IMF-3,

219 IMF-4 and IMF-5 show the intra-decadal fluctuations with the period (1-6) years in Bahawalpur

220 and (1-4) years in Barkhan. The remaining IMFs of all stations signifies the inter-decadal

221 fluctuations with periodicity $(>10)$ years. These fluctuations present the instabilities of wet and

222 dry events corresponding to each IMF. The residuals show a decreasing trend of normal dry from

223 the year 1990 to 1998 and suddenly indicates an increasing trend of normal dry from the year 2010

224 to 2018 in Figure 2(a). Figure 2(b) shows the residual stability of a normal wet trend before the

225 year 1998. Figure 2(c) shows the trend of normal wet is increasing from the year 2007. Figure 2(d)

226 shows the trend of normal wet is decreasing from the year 1990 to 2007, but the trend is gradually

227 started increasing from 2015 to onwards.

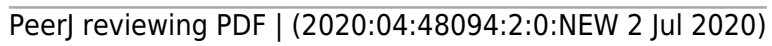


228 The EEMD procedures decomposed the SPI-3 on the sequence from the largest periodic 229 component to the smallest periodic component. The first component contains the largest 230 fluctuations of wet and dry events and gradually decreases in the fluctuations of wet and dry events 231 on the last component. Besides, the last component (residual) indicates long term weather 232 variability.

233 The significance of IMFs is tested by correlation approach (Peng et al., 2005). Initially, the 234 correlation is computed between the IMFs and SPI-3 for all stations, then the threshold is applied. 235 The correlation approach indicates that all IMFs by EEMD are statistically significant. The 236 reconstruction of SPI-3 is based on the aggregate of all IMFs and a residual. All IMFs are utilized 237 for reconstruction of SPI-3. Therefore, the MSE is computed between SPI-3 and the reconstructed 238 SPI-3. It is found that the MSE of reconstructed SPI-3 has been found in Multan, Bahawalpur, 239 Barkhan and Khanpur is $0.0024,0.0052,0.0034$ and 0.0020 , respectively.

240 The MK and SR trend tests are applied on SPI-3 of all stations to verify the reliability of residual 241 trends. Initially, SPI-3 is divided into eight periods. So that the detailed information is obtained 242 about the increasing and decreasing trends. Then the most commonly used 5\% significance level 243 is used to identify the trend. Hence, the statistical trend results of MK and SR is described in Table 2442.

245 It is shown in Table 2 that the MK and SR indicate similar results of trend identification in all 246 periods of Barkhan station. Whereas, MK and SR do not indicate similarity of trend identification 247 in 2014 for Multan, in 1994 for Bahawalpur and 1998 period for Khanpur at the 5\% level of 248 significance. The positive sign is an indication of the increasing trend, while the negative sign is 249 an indication of the decreasing trend. Moreover, the trend identification of di $\square$ erent periods by 250 MK and SR test is compared with the residuals of EEMD (Figure 2) for all stations. It turns out 
251 that the SR test indicates the consistency with residuals of EEMD in mostly periods. For instance,

252 the SR test verifies that the residuals of Multan indicate an increasing trend in 2014 while the trend

253 does not verify by the MK test (Figure 2(a)). Likewise, the residuals of Khanpur indicates a

254 decreasing trend in 1998 which is verified by the SR test, while not verified by the MK test (Figure

255 2(d)). SR and MK provide similar trend identification of periods for all stations except the above-

256 mentioned stations i.e., Multan and Khanpur.

\section{$257 \quad 3.2$ Evaluation of weather instabilities}

258 After this, there is no di $\square$ culty to apply an HT to obtain the IF and IA. We aim to describe the 259 detailed information of wet and dry events in the time-frequency domain corresponding to each

260 IMF. Therefore, HT is performed on decomposed IMFs of EEMD for all stations. Generally, HT uses the IMFs to present IF and IA corresponding to each IMF. Finally, the minimum, maximum, mean and standard deviation of IA and IF are related to each IMF is presented in Table 3 . Table 3 showed that the highest variation (based on the standard deviation of IF) was observed in IMF1 of all stations. It is an indication of non-stationarity of the SPI-3 for all stations.

The MMHS provides an aggregated amount of IA in the time-frequency domain. So MMHS has been applied on the IA and IF of IMFs for all stations. The IA and IF are related to EEMD because this was achieved after HT is applied on the decomposed IMFs of SPI-3. The MMHS plots of four stations are shown in Figure 3.

In Figure 3 (a), (b) and (d) indicate the low IF of wet and dry events at 0.1 cycles per months (about $1 / 0.1=10$ months) that is corresponding to mean IF of IMF-2 (see Table 3), while the IFs away

271 from 0.1 are indicating comparatively low IA. Figure 3(c) shows the low IF of wet and dry events 272 at 0.2 cycles per month (about $1 / 0.2=5$ months) that is corresponding to the mean IF of IMF-1 
273 (see Table 3). Besides, the IFs away from 0.2 indicate comparatively low IA. It is described that

274 Barkhan station underwent several seasonal instabilities over a short period of 5 months. Whereas,

275 Multan, Bahawalpur and Khanpur stations underwent weather instabilities over a short period of

27610 months.

277 The CWPS is performed on SPI-3 of all stations for the analysis of spectral features at the di $\square$ erent

278 time scales. The spectral features of SPI-3 can be seen in Figure 4.

279 Figure 4 shows the high energy wet and dry events with a periodicity of 32 months are identified 280 during the years (1991-2017) for all stations. Figure 4(a) and 4(b) show a spectrum of similar

281 features of wet and dry events with a period of 16 months in Multan and Bahawalpur, respectively.

282 During the years (1991-2010), the high energy wet and dry events are identified with a period of

28316 months in Khanpur (Figure 4(d)). While the high energy wet and dry events with the periodicity 284 of 16 months are identified during the years (2002-2011) in Barkhan station (Figure 4(c)). Besides, 285 some small wavelet spectrums are indicating high energy wet and dry events with 4 to 10 months 286 of periodicity for all stations. But the high strength of wet and dry events is found in Multan, 287 Bahawalpur, Barkhan and Khanpur are 1.49, 1.03, 1.42 and 1.18, respectively. All these high 288 energy wetness and dryness has been identified at the 5\% level of significance.

\section{Discussion}

In recent decades, the analysis of spatial and temporal fluctuation of wet and dry events is gain more attention (J. Huang et al., 2014). Pakistan is an agricultural country where $70 \%$ of the people's business depends on agriculture (Ahmad et al., 2004). In this paper, SPI-3 was selected to describe the Spatio-temporal fluctuation of wet and dry events. 
295 Mostly meteorological and hydrological series have non-linear and non-stationary characteristics

296 (Di et al., 2014). The SR and MK non-parametric tests were applied on di $\square$ erent periods of SPI-3

297 for the trend analysis. It is found that the SR test is indicating a trend for most of the periods as

298 compared to the MK test (Table 2). In recent years, inter-decadal time scales have been carefully

299 considered about the risk of wet and dry events trend (Baofu Li et al., 2015). Besides, EEMD was

300 applied on SPI-3 to decompose into the eight IMFs and a residual term for the trend analysis. The

301 achieved trend of wet and dry events has been compared with SR and MK identification results. It

302 is observed that the SR test indicates consistent results with EEMD residuals for all stations (Figure

3032 and Table 2). Moreover, the achieved IMFs have been used for reconstruction of SPI-3. As a

304 result, the MSE of reconstructed SPI-3 is found to be less. It means that the decompose components

305 contain the all characteristics of SPI-3. Therefore, the smaller MSE value is an indication of

306 efficient decomposition process (Gaci, S. 2016).

307

308

EEMD is a purely empirical procedure and gives complete information of the temporal attributes 309

of agricultural drought. Any non-linear and non-stationary series can be adaptively decomposed into IMF components via EEMD method, without the need to a priori basis as are Fourier and wavelet-based methods. The EEMD basis functions are known as IMF (Gaci, S. 2016; AyenuPrah, et. al. 2009). The standard deviation of IF shows high variability of wet and dry events in IMF-1 (Table 3). This variability is indicating non-stationarity of SPI-3 for all stations. HHT gives detailed information about IA and IF in dissimilar time scales, which is beneficial for discovering temporal variability 
317 of the wet and dry events in multiple time scales, but the wavelet analysis cannot give details. Intra

318 wave frequency is a traditional feature of the nonlinear process which represents IF changes in one

319 oscillation cycle. Fourier analysis cannot show the intra wave frequency, because Fourier analysis

320 is a linear structure that applies to the non-linear process. HHT is a very effective way of describing

321 IF in which intra wave frequency is revealed (Huang, 2014). MMHS indicates that during the short

322 period of 5 months, the Barkhan station has experienced severe weather instabilities, while Multan,

323 Khanpur and Bahawalpur stations have su $\square$ ered severe weather instability during the 10 months

324 (Figure 3). The di $\square$ erent spectrum’s of CWPS specifies 4 to 32 months of the periodicity of 325 wetness and dryness during the years (1991-2017) for all stations. CWPS is indicating high energy

326 weather instabilities in Multan, Barkhan, Bahawalpur and Khanpur respectively (Figure 4). It is

327 observed that the achieved short-term weather instabilities by MMHS provides consistent results

328 with CWPS for all stations. By combining the results of both procedures i.e., MMHS and CWPS,

329 it is concluded that the weather instabilities found in Multan station (1.48) is higher than Khanpur

330 (1.18) station and in Bahawalpur (1.03) it shows least weather instabilities during the short period

331 of 10 months. The intensity of weather instabilities for Barkhan station (1.42) during the short

332 period of 5 months is higher as compared to other stations. It is very important to note that the

333 MMHS provides information about weather instabilities during the short period of a month, but it

334 does not provide information about the years in which the instabilities occurred. Whereas CWPS

335 provides information about the monthly periodicity of weather instabilities for the time domain.

336 The above-mentioned points illustrate the di $\square$ erence between MMHS and CWPS.

\section{5. Conclusion}

338 In this study, we have presented a thorough analysis of four meteorological stations (Multan,

339 Bahawalpur, Barkhan and Khanpur) of Pakistan. We found that all stations are facing severe 
340 weather instabilities during the short period of 5 and 10 months using MMHS method.Moreover,

341 the CWPS has shown the weather instabilities during 4 to 32 months of periodicity for all stations.

342 Ultimately, the achieved short-term weather instabilities indicated by MMHS is consistent with

343 CWPS. We also found that the performance of the SR test is better than the MK test for EEMD

344 residuals trend analysis. In summary, these findings might be useful for water resource 345 management and policymakers.

\section{Reference}

Aguiar-Conraria, L., \& Soares, M. J. (2014). The continuous wavelet transform: Moving beyond uni- and bivariate analysis. Journal of Economic Surveys.

351 https://doi.org/10.1111/joes. 12012

Ali, S., Liu, Y., Ishaq, M., Shah, T., Abdullah, Ilyas, A., \& Din, I. (2017). Climate Change and Its Impact on the Yield of Major Food Crops: Evidence from Pakistan. Foods. Dynamics, 47(4), 437-456.

Bai, X., Shen, W., Wu, X., \& Wang, P. (2020). Applicability of long-term satellite-based precipitation products for drought indices considering global warming. Journal of Environmental Management. https://doi.org/10.1016/j.jenvman.2019.109846 
362 Bailey, W. N., \& Titchmarsh, E. C. (1938). Introduction to the Theory of Fourier Integrals. The

$363 \quad$ Mathematical Gazette. https://doi.org/10.2307/3607457

364 Caloiero, T., \& Veltri, S. (2019). Drought Assessment in the Sardinia Region (Italy) During

365 1922-2011 Using the Standardized Precipitation Index. Pure and Applied Geophysics.

366 https://doi.org/10.1007/s00024-018-2008-5

367 Caloiero, Tommaso. (2018). SPI trend analysis of New Zealand applying the ITA technique.

$368 \quad$ Geosciences (Switzerland). https://doi.org/10.3390/geosciences8030101

369 Di, C., Yang, X., \& Wang, X. (2014). A four-stage hybrid model for hydrological time series

370 forecasting. PLoS ONE. https://doi.org/10.1371/journal.pone.0104663

371 Estrela, T., \& Vargas, E. (2012). Drought Management Plans in the European Union. The Case

372 of Spain. In Water Resources Management. https://doi.org/10.1007/s11269-011-9971-2

373 Farge, M. (1992). Wavelet Transforms And Their Applications To Turbulence. Annual Review of $374 \quad$ Fluid Mechanics. https://doi.org/10.1146/annurev.fluid.24.1.395

375 Gaci, S. (2016). A new ensemble empirical mode decomposition (EEMD) denoising method for 376 seismic signals. Energy Procedia, 97(November), 84-91.

377

Griffel, D. H., \& Daubechies, I. (1995). Ten Lectures on Wavelets. The Mathematical Gazette. https://doi.org/10.2307/3620105

Grossmann, A., \& Morlet, J. (2009). Decomposmon of hardy functions into square integrable wavelets of constant shape. In Fundamental Papers in Wavelet Theory. https://doi.org/10.1515/9781400827268.126 
383 Hirsch, R. M., Slack, J. R., \& Smith, R. A. (1982). Techniques of trend analysis for monthly 384 water quality data. Water Resources Research. https://doi.org/10.1029/WR018i001p00107

385

386

387

388

389

390

391

392

393

394

395

396

397

398

399

400

401

402

403

Huang, J., Sun, S., Xue, Y., Li, J., \& Zhang, J. (2014). Spatial and Temporal Variability of Precipitation and Dryness/Wetness During 1961-2008 in Sichuan Province, West China. Water Resources Management, 28(6), 1655-1670. https://doi.org/10.1007/s11269-0140572-8

Huang, N. E., Long, S. R., \& Shen, Z. (1996). The Mechanism for Frequency Downshift in Nonlinear Wave Evolution. Advances in Applied Mechanics. https://doi.org/10.1016/S00652156(08)70076-0

Huang, N. E., Shen, Z., Long, S. R., Wu, M. C., Snin, H. H., Zheng, Q., Yen, N. C., Tung, C. C., \& Liu, H. H. (1998). The empirical mode decomposition and the Hubert spectrum for nonlinear and non-stationary time series analysis. Proceedings of the Royal Society A: Mathematical, Physical and Engineering Sciences. https://doi.org/10.1098/rspa.1998.0193

Huang, N. E., Wu, M. L., Qu, W., Long, S. R., \& Shen, S. S. P. (2003). Applications of HilbertHuang transform to non-stationary financial time series analysis. Applied Stochastic Models in Business and Industry. https://doi.org/10.1002/asmb.501

Janga Reddy, M., \& Adarsh, S. (2016). Time-frequency characterization of sub-divisional scale seasonal rainfall in India using the Hilbert-Huang transform. Stochastic Environmental Research and Risk Assessment. https://doi.org/10.1007/s00477-015-1165-7

Katz, R. W., \& Glantz, M. H. (1986). Anatomy of a rainfall index. Monthly Weather Review. https://doi.org/10.1175/1520-0493(1986)114<0764:AOARI >2.0.CO;2 
404 Kreibich, H., Di Baldassarre, G., Vorogushyn, S., Aerts, J. C. J. H., Apel, H., Aronica, G. T., 405 Arnbjerg-Nielsen, K., Bouwer, L. M., Bubeck, P., Caloiero, T., Chinh, D. T., Cortès, M., 406 Gain, A. K., Giampá, V., Kuhlicke, C., Kundzewicz, Z. W., Llasat, M. C., Mård, J., 407 Matczak, P., ... Merz, B. (2017). Adaptation to flood risk: Results of international paired 408 flood event studies. Earth's Future. https://doi.org/10.1002/2017EF000606

409 Labat, D. (2005). Recent advances in wavelet analyses: Part 1. A review of concepts. Journal of $410 \quad$ Hydrology. https://doi.org/10.1016/j.jhydrol.2005.04.003

411 Li, Baofu, Chen, Z., \& Yuan, X. (2015). The nonlinear variation of drought and its relation to 412 atmospheric circulation in Shandong Province, East China. PeerJ.

$413 \quad$ https://doi.org/10.7717/peerj.1289

Li, Bin, Su, H., Chen, F., Li, S., Tian, J., Qin, Y., Zhang, R., Chen, S., Yang, Y., \& Rong, Y. (2013). The changing pattern of droughts in the Lancang River Basin during 1960-2005. Theoretical and Applied Climatology. https://doi.org/10.1007/s00704-012-0658-2

Lim, Y. H., \& Lye, L. M. (2002). Denoising of streamflow series affected by tides using wavelet methods. Proceedings, Annual Conference - Canadian Society for Civil Engineering.

Mallat, S. G. (1989). A Theory for Multiresolution Signal Decomposition: The Wavelet Representation. IEEE Transactions on Pattern Analysis and Machine Intelligence.

Mann, H. B. (1945). Nonparametric Tests Against Trend. Econometrica. https://doi.org/10.2307/1907187 
425

426

427

428

429

430

431

432

433

434

435

436

437

438

439

440

441

442

443

444

445

in the hydrological variability of daily Seine river flow (France) between 1950 and 2008 using Hilbert-Huang Transform. Journal of Hydrology.

https://doi.org/10.1016/j.jhydrol.2012.04.052

Masud, M. B., Qian, B., \& Faramarzi, M. (2020). Performance of multivariate and multiscalar drought indices in identifying impacts on crop production. International Journal of Climatology. https://doi.org/10.1002/joc.6210

Mckee, T. B., Doesken, N. J., \& Kleist, J. (1993). The relationship of drought frequency and duration to time scales. In: Proceedings of the Ninth Conference on Applied Climatology. In American Metereological Society.

Peng, Z. K., Tse, P. W., \& Chu, F. L. (2005). A comparison study of improved Hilbert-Huang transform and wavelet transform: Application to fault diagnosis for rolling bearing. Mechanical Systems and Signal Processing. https://doi.org/10.1016/j.ymssp.2004.01.006

Sang, Y. F., Singh, V. P., Sun, F., Chen, Y., Liu, Y., \& Yang, M. (2016). Wavelet-based hydrological time series forecasting. Journal of Hydrologic Engineering. https://doi.org/10.1061/(ASCE)HE.1943-5584.0001347

Shahid, S. (2010). Rainfall variability and the trends of wet and dry periods in Bangladesh. International Journal of Climatology. https://doi.org/10.1002/joc.2053

Shi, P., Ma, X., Chen, X., Qu, S., \& Zhang, Z. (2013). Analysis of variation trends in precipitation in an upstream catchment of Huai River. Mathematical Problems in Engineering. https://doi.org/10.1155/2013/929383

Torrence, C., \& Compo, G. P. (1998). A Practical Guide to Wavelet Analysis. Bulletin of the 
American Meteorological Society. https://doi.org/10.1175/1520-

447 0477(1998)079<0061:APGTWA>2.0.CO;2

448

449

450

451

452

453

454

455

456

457

458

459

460

461

462

463

464

465

466

Trenberth, K. E. (2011). Changes in precipitation with climate change. Climate Research. https://doi.org/10.3354/cr00953

Tsakiris, G., \& Vangelis, H. (2005). Establishing a drought index incorporating evapotranspiration. European Water.

Ullah, W. (2016). Climate Change Vulnerability of Pakistan Towards Natural Disasters: A Review. International Journal of Environmental Protection and Policy. https://doi.org/10.11648/j.ijepp.20160405.13

Vicente-Serrano, S. M., Beguería, S., \& López-Moreno, J. I. (2010). A multiscalar drought index sensitive to global warming: The standardized precipitation evapotranspiration index. Journal of Climate. https://doi.org/10.1175/2009JCLI2909.1

Wang, X., Shen, H., Zhang, W., Cao, J., Qi, Y., Chen, G., \& Li, X. (2015). Spatial and temporal characteristics of droughts in the Northeast China Transect. Natural Hazards. https://doi.org/10.1007/s11069-014-1507-7

Wu, H., Svoboda, M. D., Hayes, M. J., Wilhite, D. A., \& Wen, F. (2007). Appropriate application of the Standardized Precipitation Index in arid locations and dry seasons. International Journal of Climatology. https://doi.org/10.1002/joc.1371

Wu, Z., \& Huang, N. E. (2009). Ensemble empirical mode decomposition: A noise-assisted data analysis method. Advances in Adaptive Data Analysis. https://doi.org/10.1142/S1793536909000047 
467 Yang, H., Wang, H., Fu, G., Yan, H., \& Zhao, P. (2019). Evaluation of HHT approach for

468 estimating agricultural drought trend and frequency based on modified soil water deficit

469 index (MSWDI). Theoretical and Applied Climatology. https://doi.org/10.1007/s00704-018-

$470 \quad 2688-\mathrm{x}$

471 Zhang, Q., Li, J., Singh, V. P., \& Bai, Y. (2012). SPI-based evaluation of drought events in

472 Xinjiang, China. Natural Hazards. https://doi.org/10.1007/s11069-012-0251-0

473 


\section{Table $\mathbf{1}$ (on next page)}

Table 1

Several probability distributions are fitted on the P-3 series of four meteorological stations. The $\mathrm{CV}$ represents the critical value of $\mathrm{KS}$ and $\mathrm{AD}$ test. 
1 Table 1: Several probability distributions are fitted on the P-3 series of four meteorological 2 stations. The CV represents the critical value of KS and AD test.

\begin{tabular}{lllcccc}
\hline Station & Distribution & Method & Parameter & BIC & KS test/CV & AD test/CV \\
\hline Multan & Exponential & MOM & $\mathrm{a}=0.0164$ & 3542.00 & $0.0313 / 0.0730$ & $0.4363 / 2.5018$ \\
Bahawalpur & Burr (4P) & MLE & $\mathrm{c}=994.69, \mathrm{a}=1.0053, \mathrm{~b}=52811.0, \mathrm{r}=0.60942$ & 3488.32 & $0.0324 / 0.0730$ & $0.5087 / 2.5018$ \\
Barkhan & Fitgue Life (3P) & MLE & $\mathrm{a}=0.91399, \mathrm{~b}=82.187, \mathrm{r}=-4.0011$ & 3936.46 & $0.0308 / 0.0730$ & $0.4367 / 2.5018$ \\
Khanpur & Log-normal & MOM & $\mathrm{r}=3.3099, \mathrm{~b}=1.0996$ & 3350.00 & $0.0357 / 0.0730$ & $0.5202 / 2.5018$ \\
\hline
\end{tabular}

$3 *$ The $\mathrm{b}, \mathrm{r}$ and $\mathrm{k}$ are the scale, location and rate parameter respectively. As well as both a and $\mathrm{c}$ are the shape parameter.

4 


\section{Table 2 (on next page)}

Table 2

Mann Kendall (MK) and Spearman rho (SR) trend test are applied on eight periods of SPI-3 of four stations. 
1 Table 2: Mann Kendall (MK) and Spearman rho (SR) trend test are applied on eight periods of

2 SPI-3 of four stations.

\begin{tabular}{|c|c|c|c|c|c|c|c|c|c|}
\hline \multirow[b]{2}{*}{ Station } & \multirow[b]{2}{*}{ Test } & \multicolumn{8}{|l|}{ Period } \\
\hline & & 1990s & $1994 s$ & 1998s & $2002 s$ & $2006 s$ & $2010 s$ & 2014s & 2018s \\
\hline \multirow[t]{2}{*}{ Multan } & MK & 2.3370 & -2.2629 & 2.2629 & 1.5772 & -2.5372 & 0.6172 & 1.7143 & -1.4400 \\
\hline & $S R$ & 0.6947 & -0.6713 & 0.7552 & 0.5315 & -0.7483 & 0.2098 & 0.6154 & -0.4545 \\
\hline \multirow[t]{2}{*}{ Bahawalpur } & MK & 1.0997 & -1.7143 & 3.7715 & -0.6172 & -2.5492 & 1.4400 & -2.1257 & -1.3029 \\
\hline & SR & 0.5509 & -0.5594 & 0.9510 & -0.0629 & -0.7940 & 0.4895 & -0.6923 & -0.4196 \\
\hline \multirow[t]{2}{*}{ Barkhan } & MK & 2.1995 & -0.8914 & 2.2629 & 2.1257 & -2.8115 & 2.8115 & 2.9486 & 2.9486 \\
\hline & SR & 0.6807 & -0.3357 & 0.6783 & 0.5734 & -0.7762 & 0.8252 & 0.8462 & 0.8112 \\
\hline \multirow[t]{2}{*}{ Khanpur } & MK & 0.8248 & -0.7543 & 1.8515 & -1.8515 & -1.1657 & 3.4972 & 0.6172 & 1.9886 \\
\hline & SR & 0.1754 & -0.3357 & -0.5874 & -0.5385 & -0.3776 & 0.9231 & 0.2797 & 0.6294 \\
\hline
\end{tabular}

$3 *$ Two types of characters are used for identification of trend. The bold character indicates the significance of trend

4 from MK test, while italic and bold characters indicate the significance of trend from SR test. 


\section{Table 3 (on next page)}

Table 3

The HT is applied on eight IMFs of SPI-3 of all stations. Therefore, the minimum, maximum, mean, standard deviation of IA are represented by the Min IA, Max IA, MIA and SIA respectively. Whereas, the minimum, maximum, mean and standard deviation of IF are represented by the Min IF, Max IF, MIF and SIF respectively. 
1 Table 2: The HT is applied on eight IMFs of SPI-3 of all stations. The achieved IMFs are related 2 to EEMD. Therefore, the minimum, maximum, mean, standard deviation of IA are represented 3 by the Min IA, Max IA, MIA and SIA respectively. Whereas, the minimum, maximum, mean 4 and standard deviation of IF are represented by the Min IF, Max IF, MIF and SIF respectively.

\begin{tabular}{|c|c|c|c|c|c|c|c|c|}
\hline \multicolumn{9}{|c|}{ Multan } \\
\hline \multirow[b]{2}{*}{ IMF } & \multicolumn{4}{|c|}{ Instantaneous Amplitude } & \multicolumn{4}{|c|}{ Instantaneous Frequency } \\
\hline & Min IA & $\operatorname{Max} I A$ & MIA & SIA & Min IF & Max IF & MIF & SIF \\
\hline IMF 1 & 0.018 & 1.252 & 0.359 & 0.192 & 0.000 & 0.493 & 0.243 & 0.141 \\
\hline IMF2 & 0.068 & 1.699 & 0.590 & 0.331 & 0.003 & 0.329 & 0.108 & 0.052 \\
\hline IMF 3 & 0.010 & 1.671 & 0.685 & 0.335 & 0.001 & 0.300 & 0.059 & 0.039 \\
\hline IMF 4 & 0.159 & 0.710 & 0.419 & 0.132 & 0.000 & 0.120 & 0.031 & 0.011 \\
\hline IMF 5 & 0.009 & 0.291 & 0.142 & 0.073 & 0.000 & 0.094 & 0.013 & 0.009 \\
\hline IMF 6 & 0.012 & 0.120 & 0.061 & 0.020 & 0.000 & 0.027 & 0.007 & 0.003 \\
\hline IMF 7 & 0.008 & 0.022 & 0.017 & 0.004 & 0.000 & 0.008 & 0.003 & 0.001 \\
\hline IMF 8 & 0.000 & 0.010 & 0.007 & 0.002 & 0.001 & 0.029 & 0.001 & 0.003 \\
\hline \multicolumn{9}{|c|}{ Bahawalpur } \\
\hline & \multicolumn{4}{|c|}{ Instantaneous Amplitude } & \multicolumn{4}{|c|}{ Instantaneous Frequency } \\
\hline IMF & Min IA & Max IA & MIA & SIA & Min IF & Max IF & MIF & SIF \\
\hline IMF 1 & 0.020 & 1.234 & 0.335 & 0.201 & 0.001 & 0.486 & 0.226 & 0.142 \\
\hline IMF2 & 0.022 & 1.201 & 0.502 & 0.244 & 0.008 & 0.336 & 0.111 & 0.047 \\
\hline IMF 3 & 0.015 & 1.075 & 0.556 & 0.255 & 0.008 & 0.336 & 0.111 & 0.047 \\
\hline IMF 4 & 0.168 & 0.633 & 0.406 & 0.135 & 0.000 & 0.288 & 0.056 & 0.034 \\
\hline IMF 5 & 0.037 & 0.420 & 0.172 & 0.119 & 0.025 & 0.064 & 0.034 & 0.006 \\
\hline IMF 6 & 0.012 & 0.176 & 0.107 & 0.050 & 0.000 & 0.025 & 0.010 & 0.004 \\
\hline IMF 7 & 0.019 & 0.027 & 0.023 & 0.002 & 0.000 & 0.040 & 0.006 & 0.005 \\
\hline IMF 8 & 0.000 & 0.005 & 0.004 & 0.001 & 0.001 & 0.025 & 0.001 & 0.003 \\
\hline \multicolumn{9}{|c|}{ Barkhan } \\
\hline & \multicolumn{4}{|c|}{ Instantaneous Amplitude } & \multicolumn{4}{|c|}{ Instantaneous Frequency } \\
\hline IMF & Min IA & Max IA & MIA & SIA & Min IF & Max IF & MIF & SIF \\
\hline IMF 1 & 0.002 & 1.088 & 0.321 & 0.205 & 0.000 & 0.485 & 0.217 & 0.138 \\
\hline IMF2 & 0.007 & 1.327 & 0.411 & 0.265 & 0.001 & 0.339 & 0.109 & 0.050 \\
\hline IMF 3 & 0.047 & 1.852 & 0.826 & 0.348 & 0.000 & 0.239 & 0.041 & 0.025 \\
\hline IMF 4 & 0.014 & 0.772 & 0.349 & 0.166 & 0.003 & 0.213 & 0.032 & 0.018 \\
\hline IMF 5 & 0.044 & 0.237 & 0.170 & 0.036 & 0.002 & 0.213 & 0.011 & 0.016 \\
\hline IMF 6 & 0.011 & 0.313 & 0.210 & 0.075 & 0.002 & 0.095 & 0.005 & 0.008 \\
\hline IMF 7 & 0.004 & 0.011 & 0.008 & 0.002 & 0.002 & 0.007 & 0.003 & 0.002 \\
\hline IMF 8 & 0.000 & 0.005 & 0.004 & 0.001 & 0.001 & 0.024 & 0.001 & 0.003 \\
\hline \multicolumn{9}{|c|}{ Khanpur } \\
\hline & \multicolumn{4}{|c|}{ Instantaneous Amplitude } & \multicolumn{4}{|c|}{ Instantaneous Frequency } \\
\hline IMF & Min IA & Max IA & MIA & SIA & Min IF & Max IF & MIF & SIF \\
\hline IMF 1 & 0.009 & 1.025 & 0.371 & 0.190 & 0.002 & 0.487 & 0.246 & 0.148 \\
\hline IMF2 & 0.033 & 1.448 & 0.545 & 0.260 & 0.000 & 0.303 & 0.122 & 0.050 \\
\hline IMF 3 & 0.091 & 2.347 & 0.756 & 0.487 & 0.000 & 0.136 & 0.059 & 0.021 \\
\hline IMF 4 & 0.074 & 2.009 & 0.515 & 0.424 & 0.000 & 0.088 & 0.029 & 0.011 \\
\hline IMF 5 & 0.010 & 0.518 & 0.280 & 0.149 & 0.007 & 0.086 & 0.014 & 0.009 \\
\hline IMF 6 & 0.009 & 0.146 & 0.066 & 0.046 & 0.000 & 0.046 & 0.007 & 0.005 \\
\hline IMF 7 & 0.024 & 0.034 & 0.028 & 0.003 & 0.001 & 0.005 & 0.003 & 0.001 \\
\hline IMF 8 & 0.000 & 0.006 & 0.004 & 0.001 & 0.001 & 0.219 & 0.003 & 0.017 \\
\hline
\end{tabular}


Figure 1

Figure 1

Geographical presentation of selected stations of Southern Pakistan.




Figure 2

Figure 2

The IMFs and a residual term were obtained by applying the ensemble empirical mode decomposition (EEMD) on SPI-3 of Multan (A), Bahawalpur (B), Barkhan (C) and Khanpur (D). First, SPI-3 series is depicted then the eight IMFs and a residual term is depicted. The temporal variability of IMFs are depicted on the basis of this sequence for all stations.



A
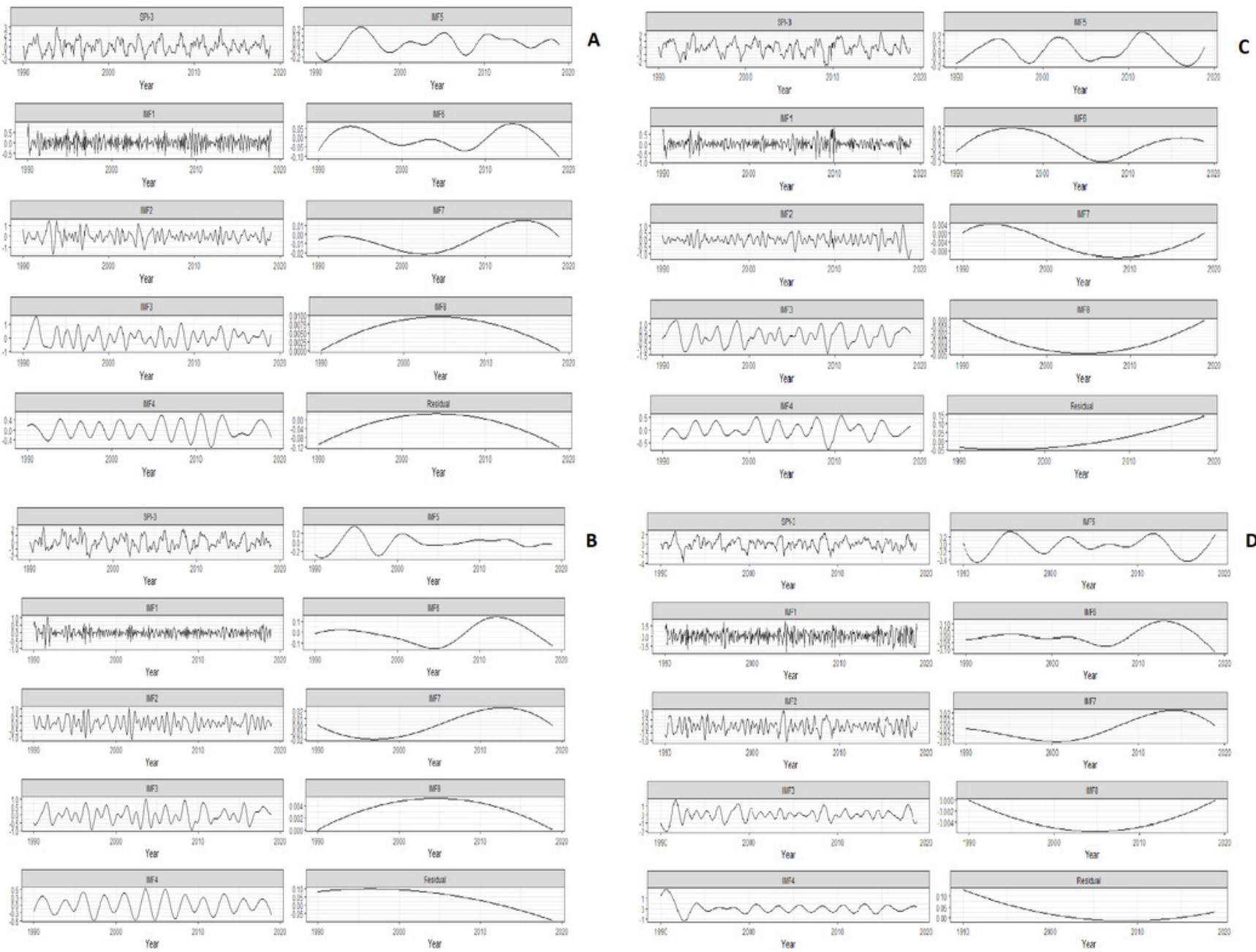
Figure 3

Figure 4

MMHS plots have been shown in the analysis of weather instabilities of Multan (A),

Bahawalpur (B), Barkhan (C) and Khanpur (D). The horizontal axis specifies the IF of wet and dry events, while the vertical axis specifies the IA of wet and dry events.
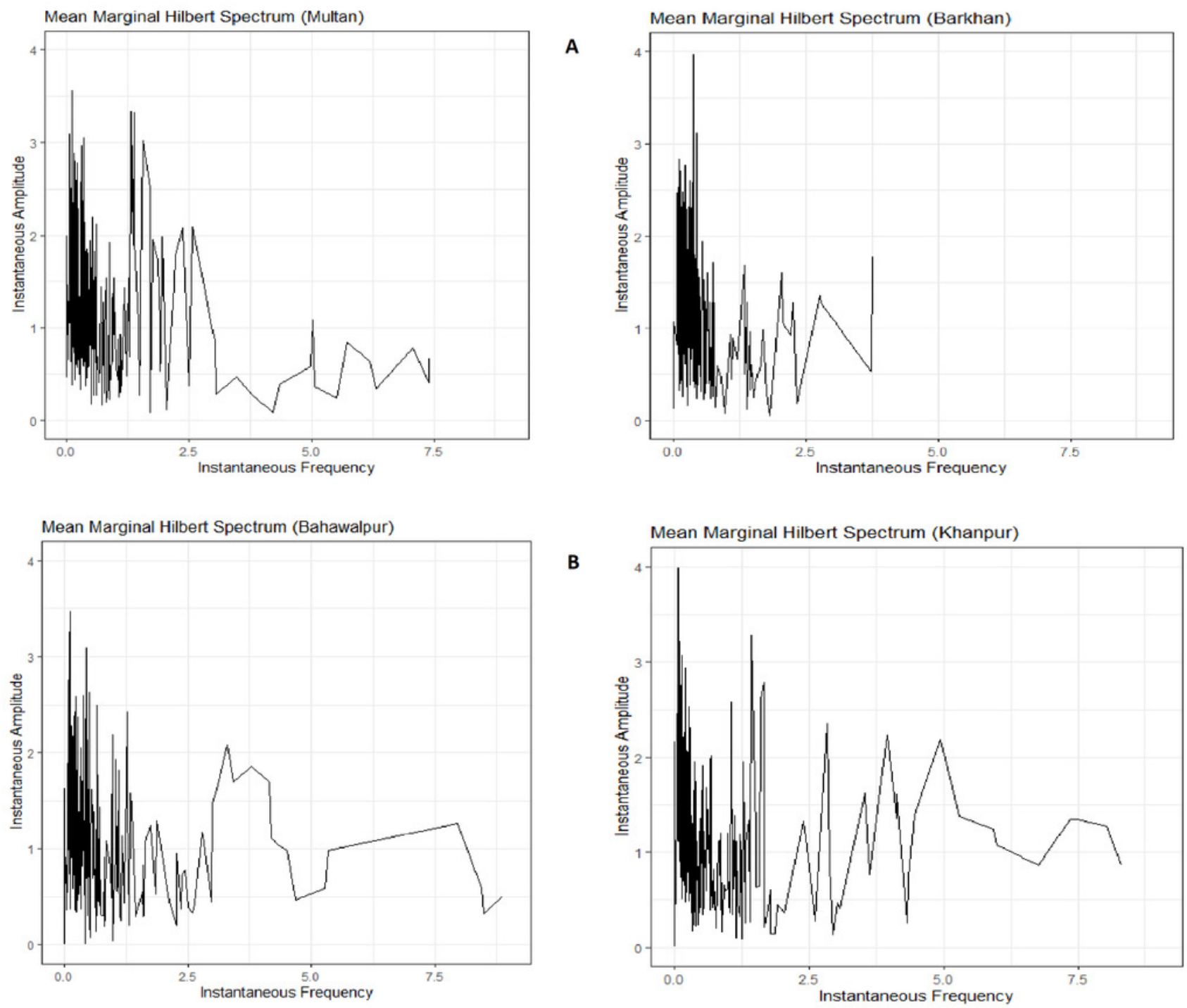

D. 


\section{Figure 4}

Figure 5

CWPS is applied on SPI-3 for Multan (A), Bahawalpur (B), Barkhan (C) and Khanpur (D). The colors of wavelet power level reveal different levels of energy and the black line indicates the $5 \%$ level of significance.

A



B

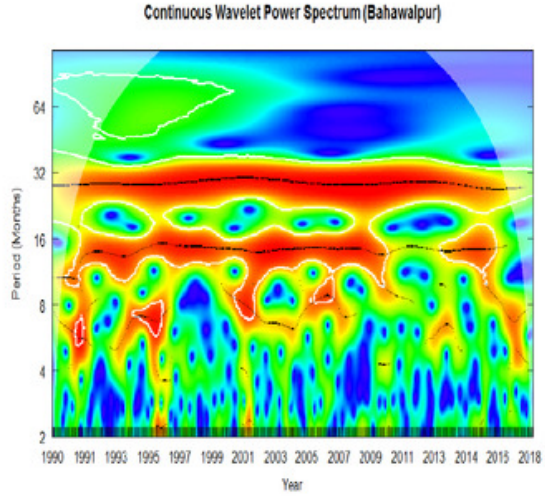

C

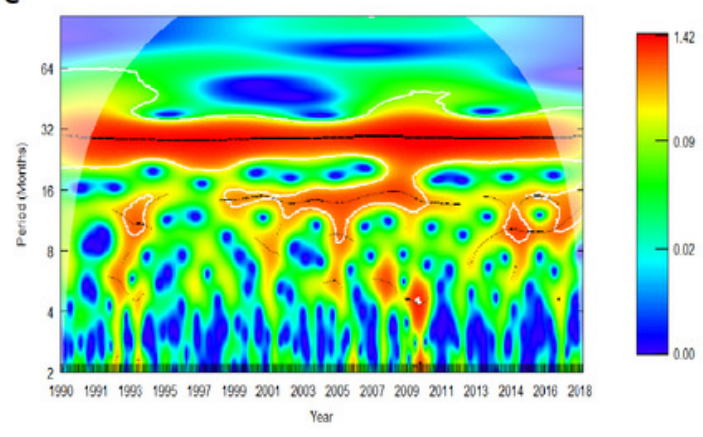

D

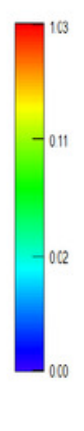

Continuous Wavelet Power Spectrum (Khanpur)

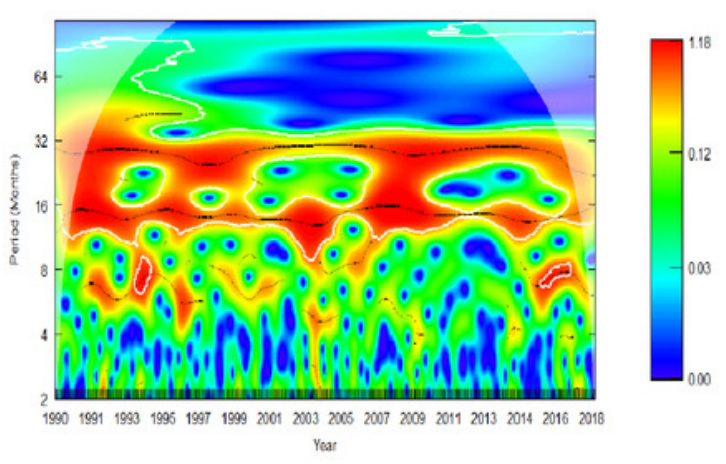

